\title{
ANÁLISE DE REDES SOCIAIS, CLASSES SOCIAIS E MARXISMO*
}

\section{Ary Cesar Minella}

\section{Introdução}

A questão que apresento neste trabalho tem sua origem em pesquisa realizada durante a década de 1980 sobre a organização e o poder dos banqueiros no Brasil. As entrevistas e a análise documental consolidaram a convicção de que era necessário levar em conta um conjunto amplo de relaçôes ou

* As primeiras consideraçôes sobre este tema foram elaboradas durante o pós-doutorado realizado no Centro de Estudos dos Direitos da Cidadania (Cenedic), no Departamento de Sociologia da Universidade de São Paulo, durante o período de maio de 2006 a abril de 2007. Agradeço imensamente a acolhida ali recebida, o ambiente estimulante de debate e a infraestrutura de pesquisa oferecida. Pesquisa realizada com apoio do CNPq. Trabalho apresentado no $35^{\circ}$. Encontro Anual da Anpocs, Caxambu, MG, outubro de 2011. conexôes dos empresários e das instituições financeiras que ocupavam o comando das entidades de classe para, assim, alcançar uma melhor compreensão da estrutura e da dinâmica das relaçōes de classe no país. Posteriormente, na percepção dessas conexões empresariais foi importante o encontro com algumas obras como a de Mintz e Schuartz (1985), em particular a análise que realizam sobre a "hegemonia financeira" e o significado que assumem as redes interempresariais constituídas pelas chamadas diretorias cruzadas (interlocking directorates), chegando assim à Análise de Redes Sociais (ARS) também conhecida como análise estrutural.

Existe uma abundante literatura sobre ARS especialmente na Europa e nos Estados Unidos, a qual nos últimos anos passou a ter maior divulgação no Brasil. ${ }^{1}$ Esta literatura destaca o aspecto interdisciplinar e a possibilidade do uso desta metodologia a partir de diferentes enfoques teóricos. É nesta perspectiva que situo minhas preocupações 
analíticas, com o objetivo de observar os alcances e os limites de seu uso para a análise das classes sociais e a pertinência de sua relação com a tradição teórica marxista. Estas são as questôes centrais do trabalho e o que se procura enfatizar é que as pesquisas com orientação marxista, especialmente as abordagem de classes sociais, podem estabelecer um promissor encontro com a ARS.

\section{O encontro com a Análise de Redes Sociais}

O início da trajetória pessoal que levou ao encontro com a ARS pode ser identificada nas intuiçōes surgidas ainda durante pesquisa empírica realizada em 1982. "Eu observava os bancários mais ativos nas negociações e ligava para o general Golbery fazer as devidas averiguações”. Transmitida no amplo e decorado gabinete-biblioteca na sede da instituição financeira, esta declaração do entrevistado, um importante banqueiro, misto de empresário e intelectual orgânico da burguesia, sinalizava para um padrão de relacionamento governo/empresários que marcaria época no período pós-golpe de $1964 .^{2}$ O banqueiro fora presidente do Sindicato dos Bancos do antigo estado da Guanabara, no período de 1962 a 1966, e importante membro de um dos principais núcleos articuladores do golpe de Estado de $1964 .{ }^{3}$ No contexto do conflito que vinha se acirrando entre banqueiros e bancários desde começo dos anos de 1960, o pós-1964 foi extremamente favorável aos primeiros, enquanto os segundos tiveram muitos dos seus líderes perseguidos e destituídos do comando de seus sindicatos.

À medida que a pesquisa empírica sobre as associações de bancos no Brasil avançava, mais crescia a convicção de que uma melhor compreensão da estrutura e da dinâmica das entidades de representação de classe deveria levar em conta um conjunto amplo de relações ou conexôes dos líderes empresariais (no caso dos presidentes e diretores das entidades), incluindo os vínculos da instituição financeira à qual estavam associados.

A relação do presidente do sindicato dos bancos com o gabinete do general Golbery, por extensão com o governo resultante do golpe de Estado, era um dado bastante significativo. Depois, cons- tatei que o presidente do sindicato que o sucedeu estava vinculado ao grupo do general Costa e Silva, na complexa disputa de poder pela sucessão do general Castelo Branco. Assim, não era nada desprezível considerar que, anos mais tarde, o presidente da Associação de Bancos do Estado de São Paulo e também da Confederação Nacional das Instituiçôes Financeiras (CNF), criada em 1985, era um dos líderes e financiadores (através do seu banco) do Instituto Liberal de São Paulo.

Neste caminho, busquei os dados mais amplos possíveis das conexões dos empresários que ocupavam o comando das entidades de classe. Muitas vezes havia participação acionária cruzada entre as instituiçõoes financeiras, ou participação conjunta em empresas não financeiras, ou ainda relações com entidades, de naturezas diversas, que reuniam empresários e membros de vários segmentos sociais, algumas delas com fachadas de entidades civis supostamente desvinculadas dos estritos interesses corporativos e políticos de seus membros.

Conservo ainda a convicção de que uma pesquisa orientada por uma concepção dialética afinal o limite das pretensões de cada um é quase inesgotável - deveria abordar "seu objeto de estudo" a partir de diversos ângulos, com as mais diversas técnicas de pesquisa que estivessem ao alcance, além de se valer de uma diversidade de fontes. Parece supérfluo dizer que este "ideal de pesquisa" serviu apenas como um norte e que, pelo caminho, os desafios da realidade e os limites do pesquisador acabaram definindo o quanto foi possível aproximar-se dele.

Aquelas constatações empíricas, e as implicações que poderiam derivar delas, permaneceram presentes ao longo dos anos. A percepção dessas conexôes empresariais como uma rede encontrou um novo caminho em 1998, durante o período de realização de programa do pós-doutorado no Departamento de Ciência Política da Unicamp. Neste período, foi de capital importância o encontro com a obra de Mintz e Schuartz (1985), como mencionado, que analisa a rede de diretorias cruzadas e a centralidade das instituições financeiras em um contexto de "hegemonia financeira". Um artigo de Swedberg (1990) chamou a atenção para as redes financeiras, mas foi a leitura de um texto de Scott (1988) que primeiro iluminou minha compreen- 
são do que seria a análise de redes sociais e estabeleceu uma primeira aproximação sistemática ao tema, preparando o terreno para futuras incursóes. Preocupado em analisar a classe capitalista, especialmente na Inglaterra, o autor indica as diversas possibilidades de redes formadas na órbita dos interesses do capital: aquelas constituídas através de participação acionária, as redes comerciais, as redes de crédito e as redes pessoais, especialmente as diretorias cruzadas, modalidade que é mais estudada pela literatura. ${ }^{4}$

Outro estímulo significativo para buscar uma aproximação maior à análise de redes sociais ocorreu quando, ao analisar a composição das diretorias das diversas entidades de representação de classe no Brasil (cada segmento financeiro tem sua própria entidade), constatei que alguns grupos ou conglomerados financeiros participavam, de forma simultânea, em várias entidades. Assim, a análise da estrutura e da dinâmica de representação de classe no setor financeiro brasileiro deveria levar em conta as conexôes que se criam entre as diversas entidades a partir da presença comum de uma mesma instituição financeira. Para isto era necessário considerar a existência de conglomerado e grupo financeiro: ${ }^{5} \mathrm{o}$ primeiro, entendido como o conjunto de empresas interligadas por controle de capital atuantes nos diversos segmentos do setor financeiro; o segundo, grupo econômico ou financeiro, interpretado como conjunto de empresas interligadas por controle de capital e que incluem também empresas do setor não financeiro. Outra pesquisa que abordou a situação dos "pequenos e médios bancos", cuja representação de interesses formal se realiza atualmente através da Associação Brasileira de Bancos (ABBC), constatou que muitos deles estavam integrados a grupos econômicos classificados entre os maiores do país (Minella, 1993).

A leitura de uma notícia publicada em jornal da grande imprensa talvez tenha sido o impulso definitivo para se considerar a possibilidade de utilizar a metodologia de análise de redes no estudo de alguns aspectos sociopolíticos do sistema financeiro. Conhecendo a atuação do Citibank nas associações de classe do sistema financeiro no Brasil, a informação de que ele atuava na diretoria da Asociación de Bancos e Instituciones Financieras de Chile parecia iluminar como um raio um fenômeno que poderia ser bem mais amplo na América Latina. Formulei então a seguinte hipótese: no contexto da implementação das políticas neoliberais no continente, que obedeceu a ritmos e intensidades diferentes em cada país (Cruz, 2004), a desregulamentação e a abertura financeiras ampliaram a presença do capital estrangeiro no setor, criando a possibilidade de que uma mesma instituição financeira atuasse de forma simultânea nas entidades de classe de diferentes paises Aquilo que havia sido constatado em relação ao Brasil, também poderia estar acontecendo em dimensão continental. Acreditei que seria necessário pesquisar esta possibilidade e pensar em suas implicações para o entendimento da estrutura e da dinâmica da organização e atuação de classe do setor financeiro.

A partir do ano 2000, uma parte da minha pesquisa procurou uma resposta a essa questão e, para dar conta dela, adotei alguns procedimentos metodológicos: a) levantamento das associações de bancos e outras entidades de representação de classe do setor financeiro existentes na América Latina; b) identificação da composição das diretorias (nome e cargo do empresário, sua instituição financeira e a origem do capital), ao mesmo tempo em que eram coletadas informações acerca do histórico das associaçōes e outros dados que possibilitassem ter uma ideia, mesmo que diminuta, sobre a atuação delas em cada país. Através dos sites das associações, do envio de questionários, contatos telefônicos ou por correio eletrônico, foi possível coletar dados considerando dois momentos. O primeiro, em 2000, incluiu dezenove associações que representavam os bancos e as instituições financeiras privadas em treze paises da América Latina, com um total de 212 cargos de direção (Minella, 2003). Mas foi apenas em 2006/2007, a partir de projeto de pesquisa desenvolvido como programa de pós-doutorado no Cenedic (Departamento de Sociologia da USP), ${ }^{6}$ que efetivamente pude apreender os fundamentos básicos da ARS e aplicá-los em um novo estudo sobre as organizaçôes de classe dos banqueiros na América Latina, incluindo agora 229 membros da diretoria de 24 associações, em 17 países (Minella, 2007). A utilização da metodologia e dos recursos tecnológicos desenvolvidos pela $\mathrm{ARS}^{7}$ permitiu 
identificar o grau de centralidade das instituiçōes financeiras (participação na diretoria das associaçōes de classe) e a conexão que se estabelece entre as associaçôes por intermédio dessas instituiçôes, constituindo assim o que se denominou de rede transassociativa na estrutura de representação de classe do setor financeiro. Constatou-se a significativa presença de alguns bancos, especialmente estadunidenses e europeus. ${ }^{8}$ Além do grau de centralidade e de outras medidas oferecidas pela ARS para analisar as conexões que se estabelecem na rede é possível sua visualização através de sociogramas. ${ }^{9} \mathrm{O}$ significado dessas conexões foi examinado à luz da literatura internacional sobre o tema (Minella, 2007).

\section{Análise de Redes Sociais: do que se trata?}

Como observam Molina e Schmidt (2006), a perspectiva da análise de redes sociais constitui um espaço único para o qual confluem diversas disciplinas e tradições intelectuais e reúne autores e instituições com interesses muito diversos. ${ }^{10}$ Convém, portanto, deixar mais claro qual é o conceito de redes sociais aqui utilizado, entre os variados usos que ele permite.

Para apresentá-lo de forma sintética, sigo as indicaçôes de Marques (2000) e Molina e Schmidt (2006), que distinguem diferentes usos possíveis para o conceito de redes sociais. O primeiro deles é a utilização de rede como metáfora. Segundo Marques, é o uso "mais antigo e disseminado, estando presente em inúmeros estudos que trabalham, às vezes, de forma periférica, com a ideia de que entidades, indivíduos ou mesmo ideias estão de alguma forma conectados entre si” (2000, pp. 31-32). Um segundo uso tem "aspecto normativo, determinando certas configurações de um dado conjunto de entidades de maneira a alcançar certos objetivos como, por exemplo, a estruturação dos fluxos e tarefas no interior de uma indústria" (Idem, p. 32). Molina e Schmidt (2006) sugerem ainda que a utilização dos diagramas de redes em projetos de participação e desenvolvimento local leva ao uso do conceito de rede social como intervenção, mediante o diagnóstico e a participação. O quarto uso do conceito de rede social é o formal, ou seja, a ARS propriamente dita, que utiliza a contribuição da teoria dos grafos e a álgebra de matrizes. Nessa direção, a análise de rede contribui para evidenciar relações e ordenações não identificadas previamente. Constitui-se, assim, em uma metodologia especifica para o estudo das relaçôes sociais. Nesse sentido, não se trata mais de considerar as redes como metáfora "da estruturação das entidades na sociedade, mas também como método para a descrição e a análise dos padrōes de relação nela presentes" (Marques, 2000, p. 32). É nessa perspectiva que utilizo o conceito na atual etapa da pesquisa. Por fim, Molina e Schmidt (2006) incluem ainda o uso do conceito de redes sociais como ponto de partida para avançar em teoria social. ${ }^{11}$

A literatura sobre análise de redes sociais destaca o seu aspecto interdisciplinar e a possibilidade de seu uso a partir de diferentes enfoques teóricos. Com esta perspectiva busca-se avaliar os alcances e os limites da metodologia para analisar as classes sociais e a pertinência de sua relação com a tradição teórica marxista.

\section{ARS, classes sociais e marxismo}

A relação do enfoque de redes sociais (também chamada análise estrutural) com a perspectiva marxista aparece referida em um conjunto de autores. Em artigo publicado em 1988, que se transformou em referencia na área, Wellman observa que no estudo dos vínculos de dependência existentes em sistemas de Estados-nação e entre grupos de interesse macroestruturais, alguns pesquisadores têm empregado conceitos analíticos estruturais, mas pouco utilizado os métodos de análise de redes sociais (p. 30). Nesta linha, Wellman considera os estudos de dependência internacionais, inter-regionais e intergrupal, incluindo os "dependentistas" (como Frank) e "os sistemas-mundo" (Wallerstein).

Quando se assume que a unidade de análise é um "sistema-mundo" e não o Estado ou a nação ou o povo, como o faz Wallerstein, a preocupação central passa a ser com as características relacionais dos Estados e menos suas características atributivas. Nessa perspectiva, as classes (e grupos de status) deixam de ser vistas "como grupos dentro de um Esta- 
do" e passam a ser tratadas como "grupos dentro de uma economia mundial” (Wellman, 1988, p. 33).

Segundo Wellman, estes trabalhos têm "conduzido outros analistas estruturais a considerar mais plenamente como é que o poder sobre o acesso a recursos afeta as relações, e a examinar os vínculos entre unidades de grande escala, como também entre pessoas", mas considera que o "efeito recíproco tem sido débil". "Seja por ignorância, ou desagrado pelo raciocínio matemático, poucos 'economistas políticos' têm empregado as ferramentas analíticas estruturais para examinar as relações entre estados e grupos de interesse" (Wellman, 1988, p. 30). Inspirado em Godelier (1978) e em The Insurgent Sociologist Journal (1979), ${ }^{12}$ Wellman afirma que:

O enfoque analítico estrutural é promissor para os estudos de corte marxista acerca de como as redes de poder-dependência estão associadas com os modos de produção - consistente com o mandato feito por Marx de que as relações de classe sejam analisadas em termos estruturais antes que categoriais (1988, p. 30).

$\mathrm{Na}$ avaliação deste autor, as técnicas de elaboração de modelos de redes poderiam proporcionar ferramentas úteis para estudar os mecanismos de câmbios estruturais a grande escala. Segundo ele, "integrar as contribuições da análise estrutural [...] com um trabalho histórico sério poderia melhorar nossa compreensão sobre tais câmbios" (Idem, p. 47, grifo meu). Ainda segundo Wellman, "os analistas estruturais consideram que as afiliaçōes categoriais refletem relações estruturais subjacentes, isto é, diferenças baseadas nos tipos de recursos com os quais eles se encontram vinculados" (Idem, pp. 32-33). Nessa perspectiva, "não tratam a classe social como um conjunto de status, ocupado por membros de uma população, mas como uma síntese para as relações econômicas de poder e dependência” (Idem, p. 33).

A relação entre a análise de redes sociais e a tradição de pensamento marxista é referida também por Emirbayer (1997). Em seu artigo "Manifesto for a relational sociology", ele observa que Marx se inscreve em uma linha analítica relacional e destaca ainda a concepção de Marx, segundo o qual, "o ca- pital não é uma coisa, mas uma relação social entre pessoas, mediada pelas coisas". Para Marx o "capital é uma relação social de produção", uma "relação histórica de produção" (1979a, p. 957, grifos no original).

Além disso, é necessário considerar a análise que Marx realiza em torno do fetichismo da mercadoria ( $O$ capital, cap. 1) e o ocultamento das relações que ele encerra. "As relações entre os produtores, nas quais se fazem efetivas as determinaçôes sociais de seus trabalhos, assumem a forma de uma relação social entre os produtos do trabalho" (Marx, 1979, p. 88). Os homens "relacionam entre si seus diversos trabalhos como trabalho humano, por quanto relacionam entre si seus produtos como valores. A relação pessoal está oculta pela forma material" (1979a, pp. 1009-1010). A relação social determinada entre os homens aparece como uma relação entre coisas, uma forma fantasmagórica que Marx chama de fetichismo.

De acordo com esse ponto de vista, o caráter fetichista do mundo das mercadorias oculta assim as relaçōes sociais sobre as quais está fundada a própria existência dessas mercadorias. Sugiro, então, que rastrear essas relações ocultas pode ser um caminho profícuo para entender as particularidades dessas relações e desvelar sua dimensão fantasmagórica, e que a análise de redes sociais pode ser extremamente útil neste procedimento.

$\mathrm{Na}$ avaliação de Pizarro, um autor que reúne em sua trajetória de pesquisa a tradição marxista com a análise de redes sociais, a identificação da exploração como a relação que fundamenta a diferença entre as classes sociais necessita avançar em termos conceituais para análises mais fecundas das posições sociais, objetivadas por suas relações mútuas nos processos de transformação e circulação dos produtos sociais. E o caminho para isto se encontra na "intersecção do marxismo e a moderna sociologia algébrica, desenvolvida para a análise das redes sociais" (1998, p. 337). No entendimento desse autor,

[...] importa destacar que a perspectiva reticular [Análise de Redes Sociais] e os métodos e técnicas de pesquisa que lhe são próprios estão contribuindo para uma reconsideração de questôes de maior amplitude e relevância para 
a grande tradição sociológica: a estrutura das elites, a função do Estado na integração social, os mecanismos de diferenciação das elites nas estruturas de classe, a natureza e função da burocracia no sentido weberiano do termo e, além disso, a interação dialética entre as estruturas de classe e as formas de 'racionalização' ou de institucionalização da dinâmica dessas estruturas (Idem, p. 377).

Ainda segundo Pizarro, a análise de redes sociais é particularmente importante para o estudo das relações intraclasse, como aquelas existentes entre os trabalhadores assalariados ou entre os empresários.

Para a perspectiva reticular [...] a estrutura das relações internas das classes ou frações de classe é o objeto privilegiado de estudo. Um postulado comum, embora às vezes implítico, das aproximações reticulares é, precisamente, que a exigência mesma de uma estrutura interna constitui o principal fator que determina a formação de uma comunidade de interesse ou, se prefirir, os procesos de coalizão de atores e a origem dos sujeitos coletivos na ação social (Idem, p. 364).

Como mencionado, um campo particular de aplicação da análise de redes sociais tem sido a composição das diretorias e conselhos administrativos das corporações tanto nos Estados Unidos como na Europa. Em termos gerais, o resultado dessas pesquisas oferece importantes contribuições para o entendimento das conexões que se estabelecem entre as corporações e da formação de uma elite empresarial e seu possível papel na circulação de informações e na articulação dos interesses capitalistas.

Alguns autores sinalizam para a necessidade de desenvolver pesquisas que levem em consideração a relação entre espaço, classe social e redes sociais. Referindo-se à classe trabalhadora, sugerem abandonar uma visão homogênea e delimitada localmente dessa classe e ver como a "formação de classe depende de uma articulação particular entre o local e o não local por tipos específicos de redes espaciais e sociais" (Blokland e Savage, 2001). ${ }^{13}$
A análise de redes sociais, como aqui está sendo considerada, pode também oferecer um caminho empírico promissor para revelar de forma mais clara a estrutura relacional na constituição e na manutenção de um "bloco no poder", conceito "desenvolvido por Nicos Poulantzas para pensar a classe burguesa como a unidade (classe social) do diverso (frações de classe) nas suas relaçôes com o Estado e com o restante da sociedade" (Boito, 2007, p. 58). A análise do bloco no poder para a realidade brasileira, como proposto por Boito, sugere uma configuração complexa de relações e vínculos sociais, políticos e econômicos, entre as próprias frações de classe e delas com o Estado que, segundo avalio, podem ser estudadas e "visualizadas" com os recursos oferecidos pela análise de redes sociais. Nesta mesma direção poderia ser contemplada a constituição de uma "nova classe social", como sugere Oliveira (2003) para o caso brasileiro recente. ${ }^{14}$

\section{Consideraçôes finais}

A declaração do banqueiro, mencionada no início deste trabalho, revela as conexôes existentes entre dois aspectos dinâmicos que, de alguma forma, são fundamentais para ação desenvolvida pelo empresário: por um lado, o relacionamento com os trabalhadores assalariados do setor - no caso, os bancários -; por outro, sua relação com o Estado e o governo em turno. Nesta se revela um tipo particular de relação, característico de uma rede de conexôes que havia se firmado no período preliminar ao golpe de Estado de 1964. De alguma forma, a rede de relações específica deste empresário, naquela conjuntura, tornou-se um elemento de particular importância na definição e nos rumos que a própria relação de classe assumiu no Brasil. Em outros termos, a configuração das redes que se estabelecem no seio das classes sociais pode matizar e redefinir aspectos da própria relação de classe social.

A capacidade real ou potencial de mobilização de uma rede em favor dos interesses específicos de classe ou de uma fração de classe ou de um bloco no poder adquire capital importância em determinadas conjunturas. Entendo que isto tem ao menos duas implicações: a primeira, para os pró- 
prios atores envolvidos na relação de classe e sua potencialidade de ação; a segunda, na percepção e no conhecimento mútuo que cada um dos atores envolvidos - indivíduos, ou grupos de uma classe têm sobre as redes de relações do outro, e das consequências disso para a própria ação. Compreendo, nesse sentido, que a análise de redes sociais pode constituir-se não apenas em uma metodologia para a pesquisa, mas em instrumento de intervenção política. Como exemplo ilustrativo: o Grupo Banco Mundial utiliza esta metodologia para coletar dados das populações que são objeto de suas políticas de financiamento, consciente de que o melhor conhecimento das reais relações que se estabelecem nas comunidades é fundamental para a implantação dessas políticas.

Os empresários inseridos no processo político e na representação de classe (atuação nas associaçôes e sindicatos) inscrevem sua ação em uma rede específica de relaçôes econômicas (empresas, grupos econômicos), políticas (vínculos partidários, financiamento de campanhas, postos legislativos), estatais (conexōes e participação na burocracia e no alto escalão dos órgãos de decisão do Estado), organizaçōes político-ideológicas e centros de pesquisa e formulação de políticas (como os Institutos Liberais, espaços acadêmicos específicos etc.), meios de comunicação social, organizaçōes militares e paramilitares, ONGs, organizações religiosas, e assim por diante. Considero que a Análise de Redes Sociais, que enfatiza as redes concretas de relaçōes sociais "que ao mesmo tempo incorporam e transcendem organizaçōes e instituições convencionais" (Mizruchi, 2006, p. 73), é um instrumento metodológico com enorme potencial para a análise do conjunto dessas relaçôes empresariais capitalistas, sua configuração estrutural intraclasse e também para as próprias relaçōes de classe.

As relações de classe não se realizam num sistema lógico-abstrato, inferido a partir das posiçōes estruturais atributivas agregadas em alto grau de abstração. Ela se constitui e se formaliza por um conjunto amplo de relaçôes, formalizadas/institucionalizadas ou não. São inúmeros os espaços relacionais e eventos constituídos pelas classes dominantes para cooptar/neutralizar as classes dominadas, na busca permanente da dominação ou do exercício hegemô- nico. Talvez o alcance delas seja maior do que supomos, por isso mesmo julgo necessária a realização de pesquisas mais claras e profundas sobre como elas se estabelecem e se mantém e qual seu resultado social e político. Minha hipótese é de que a metodologia de análise de redes sociais pode oferecer uma contribuição valiosa nesse sentido.

Em suma, a revisão bibliográfica e as observações e conclusões das pesquisas empíricas próprias sobre os banqueiros no Brasil e na América Latina levam-me a considerar que existe um caminho promissor na vinculação entre a análise ancorada no marxismo e a análise de redes sociais, concebida especialmente como uma metodologia para o exame de dados relacionais, tradição tão cara à concepção marxista.

\section{Notas}

1 São referências autores como Marques (2000, 2003, 2010), Lazzarini (2011), Lavalle et al. (2007), uma edição especial da RAE - Revista de Administração de Empresas, Fórum - Redes Sociais e Interorganizacionais, São Paulo, 46 (3), 2006. Além de coletâneas publicadas, várias dissertações e teses foram produzidas recentemente utilizando a ARS. No XV Congresso Brasileiro de Sociologia realizado em Curitiba em 2011, o GT29 "Sociologia Econômica" incluiu vários trabalhos na área (disponível em <http://www. sbsociologia.com.br/portal/index.php?option $=\mathrm{com}_{-}$ docman\&task=cat_view\&gid=178\&Itemid=171 $>$ ). ARS foi o tema de GT do XI Congresso Luso-Afro-Brasileiro de Ciências Sociais (Conlab) realizado em Salvador em agosto de 2011 (anais disponíveis em <http://www.xiconlab.eventos.dype.com.br/site/ anaiscomplementares $>$ ).

2 A entrevista ocorreu no Rio de Janeiro, por ocasião de pesquisa para minha tese de doutorado, publicada em 1988 (Banqueiros: organização e poder político no Brasil).

3 Trata-se do complexo formado pelo Instituto de Pesquisas e Estudos Sociais (IPES) e o Instituto Brasileiro de Ação Democrática (IBAD) (cf. Dreifuss, 1981).

4 Para citar apenas alguns exemplos: Scott (1997), Mizruchi (1996), Carbonai e Bartolomeo (2009). Para um estudo recente, mas com foco nas redes de participação acionária das empresas multinacionais, ver Vitali et al. (2011). 
5 Para um estudo dessa questão, ver Minella (2005 e 2005a).

6 Incluindo um estágio na Espanha onde foi possível estabelecer contato com especialistas em ARS na Universidad Autónoma de Barcelona e na Universidad Complutense de Madrid.

7 Os softwares utilizados foram o Ucinet 6 (desenvolvido por Steve Borgatti, Martin Everett e Lin Freeman) e o NetDraw (para produção dos sociogramas).

8 O Citibank participava simultaneamente de treze associaçōes de classe em sete países, e os espanhóis Santander e Bilbao Vizcaya, de sete associações em igual número de países.

9 Uma importante análise sobre a visualização das redes se encontra em Brandes et al. (2005).

10 Além da International Network for Social Network Analysis (INSNA), uma associação profissional constituída em 1978 que reúne pesquisadores da área e realiza conferência anual desde 1979, existem publicaçōes especializadas em ARS como a Social Networks (desde 1979), Connections (boletim oficial da INSNA), Journal of Social Structure (revista eletrônica) e REDES - Revista Hispana para el Análisis de Redes Sociales. Entre os softwares disponíveis para ARS encontram-se Ucinet 6, Pajek, Structure, Gradap, Krackplot, Siena e Visione. Nesta perspectiva existe um longo caminho a percorrer, e a discussão não é dissociada da análise de redes sociais enquanto método. Alguns textos apresentam sistematização e aprofundamento no debate desta questão, tais como Lozares (1996, 2005), Pizarro (1998, 2004), Uliana (2002), Emirbayer (1997), Wellman (1988), Degenne e Forsé (2004), Spinoza (2005), Mizruchi (2006). Incluo aqui os textos de Granovetter (1973, 1982 e 1985) que se tornaram referências clássicas na área.

11 Nesta perspectiva existe um longo caminho a percorrer, e a discussão não é dissociada da análise de redes sociais enquanto método. Alguns textos apresentam sistematização e aprofundamento no debate desta questão, tais como Lozares (1996, 2005), Pizarro (1998, 2004), Uliana (2002), Emirbayer (1997), Wellman (1988), Degenne e Forsé (2004), Spinoza (2005), Mizruchi (2006). Incluo aqui os textos de Granovetter (1973, 1982 e 1985) que se tornaram referências clássicas na área.

12 Cf. o texto de Maurice Godelier (1978) e The Insurgent Sociologist Journal, edição especial sobre "Marxism and Structuralism", 9 (1), 1979.

13 Outras indicações que sinalizam para esta discussão da relação classe social e redes sociais podem ser encontra- das em autores como Collyer (2003), Diane e McAdam (2003), Friedland e Palmer (1994), Overbeek (2000), Scott (2002).

14 Esta nova classe social "formou-se no consenso ideológico sobre a nova função do Estado, trabalha no interior dos controles de fundos estatais e semiestatais e está no lugar que faz a ponte com o sistema financeiro" (Oliveira, 2003, p. 148).

\section{BIBLIOGRAFIA}

BLOKLAND, Talja \& SAVAGE, Mike. (2001), "Networks, class and place". International Journal of Urban and Regional Research, 25 (2): 221-226.

BOITO JR., Armando. (2007), "Estado e burguesia no capitalismo neoliberal". Rev. Sociol. Polit, 28, jun. Disponível em <http://www.scielo. $\mathrm{br} /$ scielo.php?script=sci_arttext $\&$ pid=S0104$-44782007000100005 \& \operatorname{lng}=$ pt\&nrm=iso $>$.

BRANDES, Ulrik et al. (2005), "La explicación a través de la visualización de redes". REDES Revista Hispana para el Análisis de Redes Sociales, 9 (6), dez. Disponível em <http://revista-redes.rediris.es>.

CARBONAI, Davide. (2011), "Os administradores em comum: uma análise comparada dos capitalismos europeus em rede". Trabalho apresentado no XV Congresso Brasileiro de Sociologia, Curitiba, julho de 2011. Anais eletrônicos disponíveis em <http://www.sbsociologia.com.br/portal/ index.php?option=com_docman \&task=cat_ view $\&$ gid $=178 \&$ Itemid $=171>$ http: // www.sbsociologia.com.br/portal/index. php?option $=$ com_docman $\&$ task $=$ cat_ view\&gid=178\&Itemid=171.

CARBONAI, Davide \& BARTOLOMEO, Giovanni Di. (2009), "Interlocking directorates as a trust substitute: the italian non-life insurance industry". Trabalho apresentado no $1^{\text {st }}$ NPR (Networks, power and relations) Workshop, Milan, 16-17 september. Centro di ricerca sulle Scienze Cognitive e la Comunicazione.

CARROL, William K. \& CARSON, Colin. (2003), "The network of global corporations 
and elite policy groups: a structure for transnational capitalist class formation". Global Networks, 3 (1): 29-57.

COLLYER, Fran M. (2003), "Theorising privatisation: policy, network analysis, and class". Eletronic Journal of Sociology. Disponível em <http:// www.sociology.org/content/vol7.3/01_collyer. html >, consultado em 2 dez. 2005.

CRUZ, Sebastião C. Velasco. (2004), "Argumentos sobre as 'reformas para o mercado' nos países em desenvolvimento", in , Globalização, democracia e ordem internacional: ensaios de teoria e história, Campinas/São Paulo, Editora da Unicamp/Editora da Unesp, pp. 91-115.

DEGENNE, Alain \& FORSÉ, Michel. (2004), Les réseaux sociaux. 2. ed. Paris, Armand Colin.

DIANE, Mario \& McADAM, Doug. (2003), Social movements and networks: relational approaches to collective action. Oxford, Oxford University Press.

DREIFUSS, René. (1981), 1964 - A conquista do Estado: ação politica, poder e golpe de Estado. 3. ed. Petrópolis, Vozes.

EMYRBAYER, Mustafa. (1997), "Manifesto for a relational sociology". American Journal of Socio$\log y, 103$ (2): 281-317. Disponível em <http:// www.chssp. columbia.edu/ events/documents/ Emirbayer.pdf>, consultado em 14/4/2007.

ESPINOZA, Vicente. (2005), "Genealogia de los usos actuales del análisis de redes en Latinoamérica", in José I. Porras e Vicente Espinosa (orgs.), Redes: enfoques y aplicaciones del Análisis de Redes Sociales (ARS). Santiago do Chile, Editorial Universidad Bolivariana, pp. 15-65.

FRIEDLAND, R. \& PALMER, D. (1994), "Space, corporation and class: toward a grounded theory", in R. Friedland \& D. Boden (orgs.), Now Here: space, time and modernity. Berkeley, University of California Press.

GODELIER, Maurice. (1978), "Infrastructures, societies and history". Current Anthropology, 19 (4): 763-768.

GRANOVETTER, Mark. (1973), "The strenght of weak ties". American Journal of Sociology, 78 (6): 1360-1380.
(1982), "The strength of weak ties: a network theory revisited", in Peter V. Marsden e Nan Lin (eds.), Social structure and network analysis. Beverly Hills, Sage, pp. 105-130.

(1985), "Economic action and social structure: the problem of embeddedness". American Journal of Sociology, 91 (3): 481-510.

LAVALLE, Adrian Gurza; CASTELLO, Graziela \& BICHIR, Renata Mirandola. (2007), "Protagonistas na sociedade civil: redes e centralidades de organizaçôes civis em São Paulo". Dados, 50 (3): 465-498.

LAZZARINI, Sérgio G. (2011), Capitalismo de laços: os donos do Brasil e suas conexóes. Rio de Janeiro, Elsevier.

LOZARES, Carlos. (1996), "La teoria de redes sociales". Papers, 48. Disponível em <http:// seneca.uab.es/antropologia/ars/ars.htm>, consultado em 15/2/2006.

. (2005), "Bases metodológicas para el Análisis de Redes Sociales, ARS". Empiria Revista de Metodologia de Ciencias Sociales, 10: 9-35.

MARQUES, Eduardo Cesar. (2000), Estado e redes sociais: permeabilidade e coesão nas politicas urbanas no Rio de Janeiro. Rio de Janeiro/São Paulo, Revan/Fapesp.

(2003), Redes sociais, instituiçōes e atores politicos no governo da cidade de São Paulo. São Paulo, Annablume.

. (2010), Redes sociais, segregação e pobreza em São Paulo. São Paulo, Editora da Unesp/Centro de Estudos da Metrópole.

MARX, Karl. (1979), El Capital. Tomo 1, vol. 1: Critica de la Economia Politica. Tradução de Pedro Scaron. 8. ed. México, Siglo XXI. (1979A), El Capital. Tomo 1, vol. 3: Critica de la Economia Política. Tradução de Pedro Scaron 5. ed. México, Siglo XXI.

MINELLA, Ary C. (1988), Banqueiros: organização e poder político no Brasil. Rio de Janeiro, Espaço e Tempo/Anpocs.

. (1993), "Empresariado financeiro: organização e posicionamento no início da década de 90", in Eli Diniz (org.), Empresários e modernização econômica: Brasil anos 90. Florianópolis/São Paulo, Editora da UFSC/Idacon, pp. 69-111. 
(2003), "Globalização financeira e as associaçōes de bancos na América Latina”. Civitas - Revista de Ciências Sociais, 3 (2): 245-272. (2005), "Grupos financeiros e associações de classe do sistema financeiro", in Sonia Regina Mendonça (org.), O Estado brasileiro: agências e agentes. Niterói, EdUFF/Vício de Leitura, pp. 159-178.

(2005A), "Reestruturação do sistema financeiro brasileiro e a representação de classe do empresariado - 1994-2004", in Denise Gros, Ignacio G. Delgado, Paola Capellin e Otávio Dulci (orgs), Empresas e grupos empresariais: atores sociais em transformação. Juiz de Fora, Editora UFJF, pp. 255-277.

. (2007), "Representação de classe do empresariado financeiro na América Latina: a rede transassociativa no ano 2006". Rev. Sociol. Polit., 28: 31-56. Disponível em <http://www. scielo.br/pdf/rsocp/n28/a04n28.pdf>.

MINTZ, B. \& SCHWARTZ, M. (1985), The power structure of American business. Chicago, University of Chicago Press.

MIZRUCHI, Mark S. (1996), "What do interlocks do? An analysis, critique, and assessment of research on interlocking directorates". Annual Review of Sociology, 22: 271-298.

- (2006), "Análise de redes sociais: avanços recentes e controvérsias atuais". $R A E$ - Revista de Administração de Empresas, 46 (3): 72-86.

MOLINA, José Luis \& SCHMIDT, Samuel. (2003), "El Análisis de redes sociales en Hispano América: presente y futuro". XXIII Conferencia Internacional de Análisis de Redes Sociales en Cancún (México). Disponível em $<$ http://revista-redes.rediris.es/webredes/textos/Presente\%20y\%20futuro.htm>, consultado em 17/7/2006.

OLIVEIRA, Francisco de. (2003), "O ornitorrinco", in $\longrightarrow$ Crítica à razão dualista. O ornitorrinco, São Paulo, Boitempo, pp. 121-150.

OVERBEEK, H. (2000), "Transnational historical materialism: theories of transnational class formation and world order", in R. Palan (ed.), Global political economy: contemporary theories, Londres, Routledge, pp. 168-183.
PIZARRO, Narciso. (1998), Tratado de metodología de las ciencias sociales. Madri, Siglo Veintiuno.

. (2004), "Un nuevo enfoque sobre la equivalencia estructural: lugares y redes de lugares como herramientas para la teoría sociológica". REDES - Revista Hispana para el Análisis de Redes Sociales, 5 (2). Disponível em $<$ htpp://revista-redes.rediris.es>, consultado em 11/10/2005.

. (2005), "Solidaridad estructural y cohesión en las elites del poder en la transición española: Estado y economía”. Trabalho apresentado no IV Seminario Internacional, Culiacán, Sinaloa, México, 30 jun.

RAE - REVISTA DE ADMINISTRAÇÃO DE EMPRESAS. (2006), Fórum - Redes Sociais e Interorganizacionais, São Paulo, 46 (3): 10-86.

SCOTT, John. (1988), "Social network analysis and intercorporate relations". Hitotsubashi Journal of Commerce and Management, 23: 53-68. . (1997), Corporate business and capitalist classes. Nova York, Oxford University Press. . (2002), "Social class and stratification”. Acta Sociologica, 45 (1). Disponível em $<$ http://privatewww.essex.ac.uk/ -scottj/socscot10.htm>, consultado em 4/4/2006.

(2005), Social network analysis: a han-

dbook. 2. ed. Londres, Sage Publications.

SWEDBERG, Richard. (1990), "International financial networks and institutions". Current Sociology, 38 (2/3): 259-325.

ULIANA, Hernan A. (2002), "Network análisis e historiografia: ¿moda o desafio? Una lectura "posible" desde el punto de vista de las relaciones entre epistemología y política”. Prohistoria, 6 (6): 273-292.

VITALI, Stefania; GLATTFELDER, James B. \& BATTISTON, Stefano. (2011), "The network of global corporate control”. Disponível em <http://arxiv.org/PS_cache/arxiv/ pdf/1107/1107.5728v2.pdf>.

WELLMAN' Barry \& BERKOWITZ, S. D. (eds.), Social structure: a network approach. Cambridge, Cambridge University Press, pp. 19-61. 


\section{ANÁLISE DE REDES SOCIAIS, CLASSES SOCIAIS E MARXISMO}

\section{Ary Cesar Minella}

Palavras-chave: Análise de redes sociais; Classes sociais; Marxismo; Análise estrutural; Banqueiros na América Latina.

A perspectiva da Análise de Redes Sociais, também conhecida como análise estrutural, constitui atualmente um espaço para o qual confluem várias disciplinas e tradições intelectuais com diferentes enfoques teóricos e reúne autores e instituiçõos com interesses muito diversos. Avaliada como uma metodologia específica para o estudo das relaçōes sociais, este trabalho examina os alcances e os limites desta perspectiva para analisar as classes sociais e a pertinência de sua relação com a tradição teórica marxista. A partir de revisão bibliográfica e dos resultados de pesquisas empíricas próprias sobre os banqueiros na América Latina, considera-se que existe um caminho promissor na relação entre a análise ancorada no marxismo e o enfoque de redes sociais, concebida especialmente como uma metodologia para o exame de dados relacionais, tradiçãoo tão cara à concepção marxista.

\section{SOCIAL NETWORK ANALYSIS, SOCIAL CLASSES AND MARXISM}

Ary Cesar Minella

Keywords: Social network analysis; Social classes; Marxism; Structural analysis; Bank owners in Latin America.

The perspective of the Analysis of Social Networks, also known as structural analysis, is nowadays a space to which various disciplines and intellectual traditions converge, with different theoretical approaches, bringing together authors and institutions with much diversified interests. Considered as a specific methodology for the study of social relations, the paper examines its scope and limits for the analysis of social classes as well as the pertinence of its relation with the Marxist theory. With base on a bibliographic revision and using results of his own empirical researches on bank executives in Latin America, the author argues in favor of a promising path in the relation between the analysis based on the Marxism and the approach of the social networks, especially conceived as a methodology for examining relational data, a tradition so valued by the Marxist concepti0on.

\section{ANALYSE DES RÉSEAUX SOCIAUX, CLASSES SOCIALES ET MARXISME}

\author{
Ary Cesar Minella
}

Mots-clés: Analyse des réseaux sociaux; Classes sociales; Marxisme; Analyse structurelle; Banquiers en Amérique latine.

La perspective de l'analyse de réseaux sociaux, connue également comme analyse structurelle, constitue actuellement un espace vers lequel confluent plusieurs disciplines et traditions intellectuelles avec différentes approches théoriques et réunissant des auteurs et des institutions avec des intérêts très divers. Évalué comme une méthodologie spécifique pour l'étude des relations sociales, ce travail examine la portée et les limites de cette perspective pour analyser les classes sociales et la pertinence de sa relation avec la tradition théorique marxiste. À partir d'une révision bibliographique et des résultats de recherches empiriques propres sur les banquiers en Amérique latine, nous avons considéré qu'il existe une voie prometteuse dans la relation entre l'analyse ancrée sur le marxisme et l'approche des réseaux sociaux, conçue spécialement comme une méthodologie pour l'examen de données relationnelles, tradition chère à la conception marxiste. 